\title{
Features of cathode-anion composition of water in the reservoir subject to anthropogenic contamination
}

\author{
M.A. Derkho ${ }^{1}$, L.G. Mukhamedyarova ${ }^{1}$, D.Yu. Nokhrin ${ }^{2, *}$, A.V. Zhivetina ${ }^{1}$, and G.V. \\ Meshcheryakova $^{1}$ \\ ${ }^{1}$ South-Ural State Agrarian University, Troitsk, Russian Federation \\ ${ }^{2}$ FSBI of HE Chelyabinsk State University, Chelyabinsk, Russian Federation
}

\begin{abstract}
The assessment of the ionic composition and water quality in the Troitsky reservoir of Chelyabinsk region (Russia) was given. Water samples were taken from headstream (station 1), central (station 2) and dam (station 3) parts of the reservoir from the average level in spring (May), summer (July), autumn (September) in the period of 2019-2020. It was established that the mineral composition of water and its ecological safety depends on the season of the year and the movement of the water mass from the headstream to the dam. The highest level of ions is found in spring water samples due to flood water ingress, the smallest - in summer and autumn due to their inclusion in biota life processes. Maximum ion levels are present in water samples from the headwaters and decreases during the water movement towards the dam. In terms of metals' index for chromium (VI), manganese (excluding the year of 2019), iron and nickel, water corresponds to the "slightly polluted" category; cadmium and lead - "clean"; aluminum, copper, and zinc - "clean". By the WPI magnitude regardless of the season of the year and the sampling point, the water belongs to the 3rd quality class "moderately polluted". Being ampholytes, lead, aluminum, and zinc in water with a weakly alkaline medium reaction increase their reactivity and due to this directly affect not only the concentration of each other, but also the level of iron, nickel, and copper. The variability formation of cathode-anion composition of water in the reservoir based on PCA results is by $86.2 \%$ due to the influence of natural and anthropogenic factors. Priority water pollutants (chromium (VI), nickel, manganese) enter the reservoir from specific anthropogenic sources, as evidenced by the ranking of indicators by residual unexplained variance value.
\end{abstract}

\section{Introduction}

Reservoirs play an important role in the accumulation and conservation of fresh water throughout the world. In addition, they are used as cooling reservoirs, providing technological processes in hydroelectric power plants, flood control, irrigation, and

\footnotetext{
* Corresponding author: nokhrin8@mail.ru
} 
recreational purposes $[1,2,3,4]$. Therefore, their number is constantly increasing. Most reservoirs are created along the beds of small and medium rivers, changing its hydrodynamic characteristics [5], that is, belong to the river type.

Water quality in reservoirs is determined by natural and anthropogenic factors, the totality of which affect the ratio of abiotic and biotic components in its ecosystem. At the same time, most of the research on this problem is devoted to the influence assessment of the dam on hydrodynamic and biogeomorphological processes in river sections located below the flow $[1,5]$. At the same time, biotic and abiotic interactions in the water area of the reservoir are little studied.

The chemical composition of water plays an important role in the formation of the reservoir ecosystem as its quality determines the state of bottom sediments, the exchange nature at the water - bottom sediments boundary, biota development level, reservoir trophicity, etc. [6]. Thus, the acid-base and redox properties of water are associated with the content of basic cations and anions, including heavy metals. Exceeding their quantity in water over normative quality indicators level determines its potential toxicity for living organisms [7]. The concentration of most components in water is associated with their solubility in water, the ability to interact with organic substances, reaction of the medium, anthropogenic load [3].

The cathode-anion composition of natural waters has purely regional features, which is determined both by geochemical features of the territories and the specifics of pollutants associated with the level of industry development $[8,9,10,11,12]$. Thus, as one of the industrialized regions of Russia, the anthropogenic load on water bodies in Chelyabinsk region is combined with lithogenous characteristics of the Earth crust [13, 14], collectively defining the ecological condition of environmental components [15]. Thus, as other natural environments, water quality is very dependent on heavy metals pollution coming from industrial discharges, wastewater, etc. [16]. Seasonal and annual variability in concentrations of pollutants entering natural waters determines the need for regular monitoring of their quality.

The purpose of this study was to assess the cathode-anion composition and water quality in the Troitsky reservoir of Chelyabinsk region created in 1960 as a cooling reservoir of the Troitsky hydroelectric power plant and excluded from its technological cycle in 2019.

\section{Materials and methods}

Troitsky reservoir (Figure 1) is located in the southern forest-steppe zone of the Chelyabinsk region. It is located after the confluence of Uvel'ka and Uy rivers in the Troitsky municipal district, bordering in the lower part with Kostanay region (Republic of Kazakhstan), is the second one in the reservoirs' cascade on the Uvel'ka river, belongs to the bed type, the shoreline is heavily indented, the surface and catchment area is 10.85 and $15100,00 \mathrm{~km}^{2}$, the water volume is 45.10 million $\mathrm{m}^{3}$, the water exchange coefficient is 9.44 and the regulation of river runoff is seasonal (maximum in April) [17].

The study area included three stations: I station - headstream part, II station - central part, and III station - the dam part of the reservoir. Water sampling was carried out from the middle horizon in spring (May), summer (July) and autumn (September) in 2019 and 2020 in accordance with the requirements of GOST R 51592-2000 [18]. Laboratory tests were performed on the basis of LLC "Troitsky water and wastewater treatment plant" (Troitsk, Chelyabinsk region). 


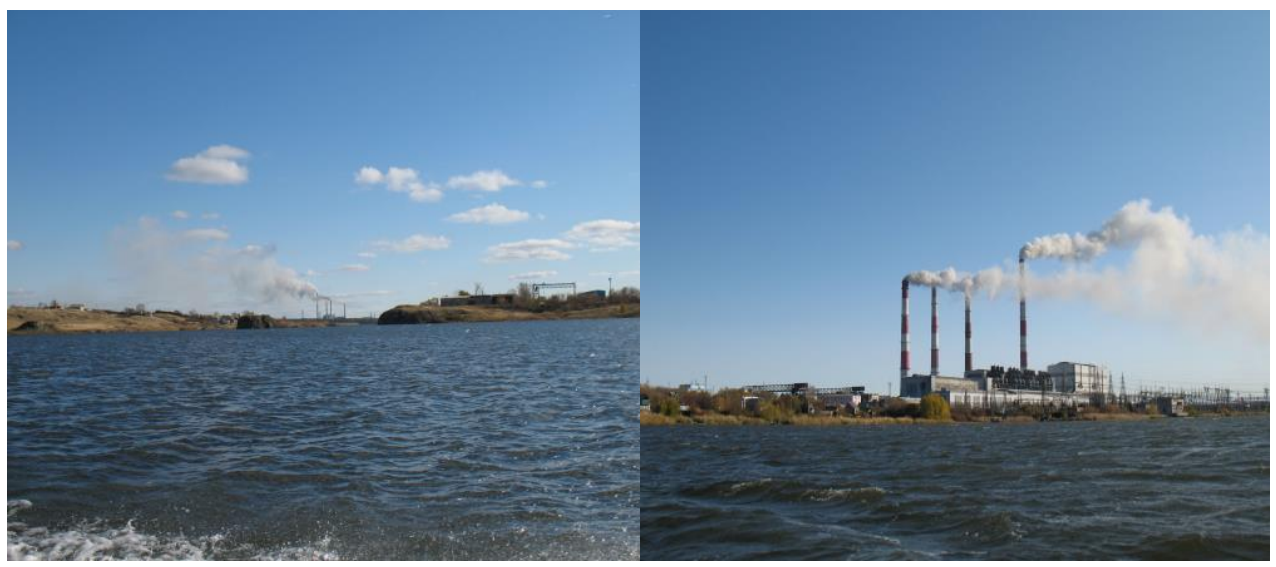

a)

b)

Fig. 1. General view of the Troitsky reservoir: a) headstream; b) central part.

For the characteristics of the chemical composition and ecological state of water, the following indicators were determined: $\mathrm{pH}$ according to PND F 14.1:2:3:4.121-97 [19], dissolved oxygen - PND F 14.1:2.101-97 [20], BOD 5 - NDP 10.1:2:3.131-2016 [21], carbonates and bicarbonates according to GOST 31957 - 2012 [22]; chlorides according to PND F 14.1:2:3.96-97 [23], sulphates - PND F 14. 1:2.159-2000 [24], fluorides - PND F 14.1:2:3:4.179-2002 [25]; calcium, magnesium, potassium, and sodium according to GOST 31869-2012 [26]; aluminum according to GOST 18165-2014 [27]; total iron - PND F 14.1:2:4.50- 96 [28], chrome (VI), manganese, nickel, copper, zinc, cadmium, lead - PND F 14.1:2:4.139-98 [29]. The data obtained were compared with the requirements of GN 2.1.5.1315-03 [30].

To assess the environmental safety of water for heavy metals, the metal index $(M I)$ was calculated according to the following formula [16]:

$$
M I=\sum_{i=1}^{N} \frac{C_{i}}{\mathrm{MPC}}
$$

Where $C_{i}$ is the concentration of metal in the water sample, $\mathrm{mg} / \mathrm{dm}^{3}$, MPC - maximum permissible metal concentration $\left(\mathrm{mg} / \mathrm{dm}^{3}\right)$ in accordance with the requirements of regulations for household waters [30].

The metal index makes it possible to make an idea of water contamination degree with heavy metals, especially toxic, since water is assigned a certain quality class and category (Table 1).

Table 1. Water quality categories by metal index (given by Withanachchi et. al., 2018 [16]).

\begin{tabular}{|c|c|l|}
\hline Metals' index (MI) value & Water quality class & \multicolumn{1}{|c|}{ Pollution category } \\
\hline$<0,3$ & I & Very clean \\
\hline $0,3-1,0$ & II & Clean \\
\hline $1,0-2,0$ & III & Slightly polluted \\
\hline $2,0-4,0$ & IV & Moderately polluted \\
\hline $4,0-6,0$ & V & Heavily polluted \\
\hline$>6,0$ & VI & Severely polluted \\
\hline
\end{tabular}

According to [31], the MI value greater than 1.0 indicates excessive flow of metals into the water source initiating a decrease in its quality and environmental safety. 
The Water Pollution Index (WPI) was used for the integrated assessment of water quality in the reservoir, which was calculated according to the following formula [32]:

$$
W P I=\frac{\sum\left(C_{1-6} / M P C_{1-6}\right)}{6}
$$

Where $C / M P C$ is the normalized parameter concentration in the water sample, 6 - a strictly limited number of parameters.

Dissolved oxygen and biochemical oxygen demand after 5 days of incubation $\left(\mathrm{BOD}_{5}\right)$ were included as mandatory parameters when calculating the WPI. In our studies, their levels ranged from 7.13 to 12.30 and 1.34 to $4.67 \mathrm{mg} / \mathrm{dm}^{3}$, respectively. The remaining indicators were chosen based on the ranking of their concentrations relative to MPC [30]. The criteria for determining MPC for dissolved oxygen and $\mathrm{BOD}_{5}$ were used in the WPI calculation, as presented in table 2 .

Table 2. MPC for dissolved oxygen and $\mathrm{BOD}_{5}$ in WPI calculation (given according to Gagarin, 2012 [33]; Pimenova, 2017 [32]).

\begin{tabular}{|l|c|c|c|c|c|}
\hline $\mathrm{BOD}_{5}, \mathrm{mg} \mathrm{O}_{2} \mathrm{dm}^{3}$ & Norm & $\begin{array}{l}\text { Dissolved oxygen, } \\
\mathrm{mg} / \mathrm{dm}^{3}\end{array}$ & Norm & $\begin{array}{l}\text { Dissolved oxygen, } \\
\mathrm{mg} / \mathrm{dm}^{3}\end{array}$ & Norm \\
\hline Up to 3 inclusively & 3 & Over 6 & 6 & $4 \ldots 3$ & 30 \\
\hline More than 3 to 15 & 2 & $6 \ldots 5$ & 12 & $3 \ldots 2$ & 40 \\
\hline Over 15 & 1 & $5 \ldots 4$ & 20 & $2 \ldots 1$ & 50 \\
\hline & & & & $1 \ldots 0$ & 60 \\
\hline
\end{tabular}

The water quality class was determined based on the criteria in Table 3.

Table 3. Criteria for water quality assessment by WPI (as per Gagarin, 2012 [33]).

\begin{tabular}{|c|c|l|}
\hline WPI value & Water quality class & \multicolumn{1}{|c|}{ Pollution category } \\
\hline up to 0.3 & 1 & Very clean \\
\hline more than 0.3 to 1.0 & 2 & Clean \\
\hline more than 1.0 to 2.5 & 3 & Moderately polluted \\
\hline more than 2.5 to 4.0 & 4 & Polluted \\
\hline more than 4.0 to 6.0 & 5 & Dirty \\
\hline more than 6.0 to 10.0 & 6 & Very dirty \\
\hline more than 10 & 7 & Extremely dirty \\
\hline
\end{tabular}

The application "Data Analysis Package" in the program "Microsoft Office Excel 2007" was used in the statistical analysis of the obtained data. The method of Principal component analysis (PCA) was used to determine the factors influencing the variability of chemical water indicators, as well as to explain the contribution of natural and anthropogenic processes to their variability, which allows to characterize the water parameters dispersion by identifying their linear combinations - the main component [34]. With this, a single correlation matrix was subjected to this analysis, in which all the indicators included were equivalent and no restrictions were imposed on their joint variation. In our study, the PCA method was used to characterize the structure of total variability in water indicators in the reservoir. The number of the most important and sufficient factors was determined by means of a "scree plot" criteria chart by R. Cattell [35]. The randomization Monte Carlo method ( $n=999)$ was used to assess the statistical significance of the main component, and the importance of chemical water indicators' contribution to the main component was determined by Pearson correlation between an individual indicator and its load on the main component. Calculations were made in the vegan package (version 2.5-7 [36]) for the 
statistical environment $\mathrm{R}$ (version 4.0.3 [37]). The effects at $\mathrm{P} \leq 0.05$ were considered statistically significant.

To rank indicators by the share of unexplained variance (in \%), recommendations [38] were used, according to which the accumulated (cumulative) contribution share of all explained components (last column of Table 8) was subtracted from the main component load and multiplied by $100 \%$.

\section{Results}

The determination results of the $\mathrm{pH}$ level, concentration of main cations and anions, trace elements defined in the conditions of Troitsky water and wastewater treatment plant laboratory are given in Tables 4 and 5 .

The reaction of the medium $(\mathrm{pH})$ in 2019 and 2020 was in the range from 7.11 to 8.69 units, that is, it changed within the slightly alkaline values of the $\mathrm{pH}$ scale. The magnitude depended not so much on the sampling station as on the season of the year. The $\mathrm{pH}$ values closest to the neutral medium reaction were recorded during the spring and summer periods of the year.

Regardless of the season of the year and stations, the level of main ions in $2019-2020$ did not exceed MPC values [30], but their number especially increased in the spring (during the flood period). Bicarbonates and sulphates dominated among the anions of natural water, among cations - magnesium and calcium, which allows it to be attributed to the bicarbonate (or mixed) class and magnesium-calcium group.

When analyzing the water samples composition from the reservoir, it was found that manganese, iron, nickel, and chromium were dominant elements which level exceeded the MPC values during all studies. The concentrations of metals such as aluminum, copper, zinc, cadmium, and lead did not exceed the recommended norms. At the same time, a general trend was revealed in the water mineral composition change: the level of metals increased sharply in the spring period of the year, especially in the headstream of the reservoir, decreased in summer and autumn periods, most strongly - in the dam part (Table 5).

Table 4. Content of main ions and carbonates $\left(\mathrm{mg} / \mathrm{dm}^{3}\right)$ in reservoir water samples.

\begin{tabular}{|c|c|c|c|c|c|c|c|c|c|c|}
\hline \multirow{3}{*}{ Indicators } & \multicolumn{9}{|c|}{ Season / Station } & \multirow{3}{*}{$\mathrm{MPC}^{*}$} \\
\hline & \multicolumn{3}{|c|}{ Spring } & \multicolumn{3}{|c|}{ Summer } & \multicolumn{3}{|c|}{ Autumn } & \\
\hline & 1 & 2 & 3 & 1 & 2 & 3 & 1 & 2 & 3 & \\
\hline \multicolumn{11}{|c|}{2019} \\
\hline $\begin{array}{l}\text { Hydrogen ion } \\
\text { exponent, pH }\end{array}$ & 7.41 & 7.47 & 7.49 & 7.93 & 7.45 & 7.19 & 8.69 & 8.47 & 8.16 & - \\
\hline Hydrocarbonates & 261.9 & 271.5 & 290.8 & 285.7 & 288.7 & 312.2 & 243.4 & 271.2 & 284.3 & - \\
\hline Chlorides & 67.2 & 63.7 & 63.0 & 54.3 & 51.0 & 51.0 & 53.7 & 54.8 & 56.7 & 350 \\
\hline Sulphates & 228.7 & 209.6 & 201.8 & 149.5 & 147.8 & 132.3 & 178.5 & 170.7 & 166.4 & 500 \\
\hline Carbonates & 0.40 & 0.48 & 0.54 & 1.42 & 0.48 & 0.29 & 6.67 & 4.64 & 2.45 & - \\
\hline Fluorides & 0.72 & 0.67 & 0.66 & 0.43 & 0.41 & 0.53 & 0.61 & 0.63 & 0.66 & 1,2 \\
\hline Potassium & 4.2 & 5.8 & 6.0 & 10.0 & 11.8 & 13.5 & 7.9 & 8.7 & 9.3 & 30 \\
\hline Sodium & 47.6 & 49.6 & 55.0 & 62.1 & 67.9 & 72.1 & 45.9 & 47.2 & 50.6 & 200 \\
\hline Calcium & 56.3 & 60.9 & 61.4 & 70.2 & 76.4 & 78.1 & 64.6 & 79.5 & 93.2 & - \\
\hline Magnesium & 40.5 & 43.4 & 49.4 & 32.0 & 33.6 & 38.9 & 44.5 & 49.8 & 53.2 & 50 \\
\hline \multicolumn{11}{|c|}{2020} \\
\hline $\begin{array}{l}\text { Hydrogen ion exp } \\
\text { onent, } \mathrm{pH}\end{array}$ & 7.29 & 7.56 & 7.59 & 7.28 & 7.16 & 7.11 & 8.50 & 8.42 & 8.33 & - \\
\hline Hydrocarbonates & 213.5 & 265.3 & 290.6 & 295.9 & 300.4 & 324.3 & 276.3 & 282.3 & 296.7 & - \\
\hline Chlorides & 67.1 & 62.1 & 60.0 & 54.1 & 49.7 & 38.0 & 59.9 & 55.6 & 57.4 & 350 \\
\hline Sulphates & 218.1 & 213.5 & 197.7 & 129.6 & 125.7 & 119.0 & 178.5 & 166.0 & 160.0 & 500 \\
\hline Carbonates & 0.25 & 0.71 & 0.67 & 0.33 & 0.26 & 0.25 & 5.03 & 4.29 & 3.70 & - \\
\hline Fluorides & 0.75 & 0.67 & 0.63 & 0.58 & 0.60 & 0.62 & 0.50 & 0.51 & 0.63 & 1,2 \\
\hline
\end{tabular}




\begin{tabular}{|l|c|c|c|c|c|c|c|c|c|c|}
\hline Potassium & 4.3 & 5.9 & 6.4 & 9.6 & 13.8 & 14.6 & 8.7 & 9.0 & 9.7 & 30 \\
\hline Sodium & 49.8 & 50.3 & 54.1 & 60.3 & 66.4 & 67.3 & 50.1 & 52.0 & 56.9 & 200 \\
\hline Calcium & 63.5 & 66.0 & 68.5 & 87.8 & 90.2 & 93.5 & 71.6 & 72.0 & 79.5 & - \\
\hline Magnesium & 21.3 & 22.6 & 27.8 & 36.6 & 38.4 & 39.7 & 43.3 & 43.2 & 44.2 & 50 \\
\hline
\end{tabular}

Note: * - MPC [30]

Table 5. Trace elements and heavy metals $\left(\mathrm{mg} / \mathrm{dm}^{3}\right)$ in reservoir water samples.

\begin{tabular}{|c|c|c|c|c|c|c|c|c|c|c|}
\hline \multirow{3}{*}{ Indicators } & \multicolumn{9}{|c|}{ Season / Station } & \multirow{3}{*}{$\mathrm{MPC}^{*}$} \\
\hline & \multicolumn{3}{|c|}{ Spring } & \multicolumn{3}{|c|}{ Summer } & \multicolumn{3}{|c|}{ Autumn } & \\
\hline & 1 & 2 & 3 & 1 & 2 & 3 & 1 & 2 & 3 & \\
\hline \multicolumn{11}{|c|}{2019} \\
\hline Aluminum & 0.053 & 0.050 & 0.030 & 0.011 & 0.006 & 0.007 & 0.030 & 0.018 & 0.009 & 0.2 \\
\hline Chromium VI & 0.152 & 0.120 & 0.110 & 0.061 & 0.058 & 0.051 & 0.054 & 0.052 & 0.053 & 0.05 \\
\hline Manganese & 0.600 & 0.500 & 0.450 & 0.120 & 0.110 & 0.107 & 0.108 & 0.120 & 0.110 & 0.1 \\
\hline Total iron & 0.56 & 0.48 & 0.32 & 0.36 & 0.32 & 0.31 & 0.40 & 0.35 & 0.33 & 0.3 \\
\hline Nickel & 0.029 & 0.027 & 0.024 & 0.029 & 0.026 & 0.025 & 0.025 & 0.021 & 0.020 & 0.02 \\
\hline Copper & 0.085 & 0.074 & 0.072 & 0.022 & 0.018 & 0.017 & 0.023 & 0.020 & 0.020 & 1.0 \\
\hline Zinc & 0.060 & 0.053 & 0.020 & 0.014 & 0.009 & 0.008 & 0.014 & 0.010 & 0.009 & 1.0 \\
\hline Cadmium & 0.001 & 0.001 & 0.0009 & 0.0005 & 0.0004 & 0.0005 & 0.0004 & 0.0002 & 0.0002 & 0.001 \\
\hline Lead & 0.010 & 0.005 & 0.005 & 0.005 & 0.003 & 0.003 & \begin{tabular}{|l|}
0.004 \\
\end{tabular} & 0.004 & 0.004 & 0.01 \\
\hline \multicolumn{11}{|c|}{2020} \\
\hline Aluminum & 0.087 & 0.065 & 0.038 & 0.029 & 0.026 & 0.025 & 0.016 & 0.009 & 0.008 & 0.2 \\
\hline Chromium VI & 0.062 & 0.058 & 0.051 & 0.100 & 0.090 & 0.064 & 0.053 & 0.052 & 0.052 & 0.05 \\
\hline Manganese & 0.250 & 0.210 & 0.200 & 0.136 & 0.112 & 0.111 & 0.109 & 0.104 & 0.102 & 0.1 \\
\hline Total iron & 0.83 & 0.60 & 0.54 & 0.58 & 0.38 & 0.33 & 0.37 & 0.32 & 0.31 & 0.3 \\
\hline Nickel & 0.035 & 0.032 & 0.030 & 0.027 & 0.022 & 0.021 & 0.026 & 0.021 & 0.021 & 0.02 \\
\hline Copper & 0.079 & 0.054 & 0.047 & 0.014 & 0.012 & 0.010 & 0.011 & 0.010 & 0.010 & 1.0 \\
\hline Zinc & 0.081 & 0.064 & 0.042 & 0.018 & 0.007 & 0.006 & 0.015 & 0.009 & 0.007 & 1.0 \\
\hline Cadmium & 0.0005 & 0.0005 & 0.0005 & 0.0010 & 0.0001 & 0.0001 & 0.0009 & 0.0003 & 0.0003 & 0.001 \\
\hline Lead & 0.010 & 0.005 & 0.004 & 0.005 & 0.002 & 0.002 & 0.004 & 0.003 & 0.002 & 0.01 \\
\hline
\end{tabular}

Note: * - MPC [30]

An assessment of the environmental water safety in the reservoir by metal content based on MI is presented in Table 6. Only the season of the year was considered in its calculation as it gives a general indication of the level of metals' excess in water samples, as well as the MPC values regulated by GN 2.1.5.1315-03 [30].

A similar trend was revealed in 2019 and 2020 when ranking metals considering the water quality class: in terms of the content of aluminum, copper and zinc, reservoir water was classified as "very clean", by the amount of cadmium and lead - "clean", by the level of chromium (VI), iron, nickel, and manganese (excluding 2019) — "slightly polluted". Hence, priority water pollutants were manganese, iron, chromium (VI) and nickel (Table 6).

Table 6. Water quality by metal index.

\begin{tabular}{|c|c|c|c|c|c|c|}
\hline \multirow[t]{2}{*}{ Indicator } & \multicolumn{3}{|c|}{ MI values by seasons of the year } & \multirow[t]{2}{*}{ MI average } & \multirow{2}{*}{$\begin{array}{c}\text { Water } \\
\text { quality } \\
\text { class }\end{array}$} & \multirow[t]{2}{*}{ Pollution category } \\
\hline & spring & summer & autumn & & & \\
\hline \multicolumn{7}{|c|}{2019} \\
\hline Aluminum & 0.22 & 0.04 & 0.10 & 0.12 & $\mathrm{I}$ & Very clean \\
\hline Chromium VI & 2.54 & 1.13 & 1.06 & 1.58 & III & Slightly polluted \\
\hline Manganese & 5.16 & 1.12 & 1.13 & 2.47 & IV & Moderately polluted \\
\hline Iron & 1.51 & 1.10 & 1.20 & 1.27 & III & Slightly polluted \\
\hline Nickel & 1.33 & 1.33 & 1.10 & 1.25 & III & Slightly polluted \\
\hline Copper & 0.08 & 0.02 & 0.02 & 0.04 & I & Very clean \\
\hline
\end{tabular}




\begin{tabular}{|l|l|l|l|l|l|l|}
\hline Zinc & 0.04 & 0.01 & 0.01 & 0.02 & I & Very clean \\
\hline Cadmium & 0.97 & 0.47 & 0.27 & 0.57 & II & Clean \\
\hline Lead & 0.67 & 0.37 & 0.40 & 0.48 & II & Clean \\
\hline \multicolumn{7}{|c|}{2020} \\
\hline Aluminum & 0.31 & 0.13 & 0.06 & 0.17 & I & Very clean \\
\hline Chromium VI & 1.14 & 1.69 & 1.05 & 1.29 & III & Slightly polluted \\
\hline Manganese & 2.20 & 1.20 & 1.05 & 1.48 & III & Slightly polluted \\
\hline Iron & 2.19 & 1.43 & 1.11 & 1.58 & III & Slightly polluted \\
\hline Nickel & 1.62 & 1.17 & 1.13 & 1.30 & III & Slightly polluted \\
\hline Copper & 0.06 & 0.12 & 0.10 & 0.09 & I & Very clean \\
\hline Zinc & 0.06 & 0.01 & 0.01 & 0.03 & I & Very clean \\
\hline Cadmium & 0.50 & 0.40 & 0.50 & 0.47 & II & Clean \\
\hline Lead & 0.63 & 0.30 & 0.30 & 0.41 & II & Clean \\
\hline
\end{tabular}

The same type of seasonal and inter-annual MI variability allowed to determine the water pollution index (WPI) not by individual years, but for the period of 2019-2020.

For the WPI calculation, we selected 6 indicators, including mandatory - the content of dissolved oxygen and $\mathrm{BOD}_{5}$ and limiting - chromium (VI), iron, manganese and nickel (Table 7) .

Calculation of the Integral Water Pollution Index (WPI) showed that regardless of the season of the year and the selection point, the studied water had the 3rd quality class and was characterized as moderately polluted (WPI value "over 1.0 to 2.5"). However, it should be noted that the WPI values were highest in the spring (2.36 for headstream; 1.99 for the central part and 1.81 - the dam part). In summer and autumn, the WPI was between 1.11 and 1.31 .

Table 7. Characteristics of water pollution in the reservoir by the WPI magnitude for the period of 2019-2020

\begin{tabular}{|c|l|l|c|c|}
\hline Station & $\begin{array}{c}\text { Season of the } \\
\text { year }\end{array}$ & WPI & $\begin{array}{c}\text { Water } \\
\text { quality class }\end{array}$ & Contamination characteristic \\
\hline \multirow{3}{*}{ Station I } & Spring & 2.36 & III & Moderately polluted \\
\cline { 2 - 5 } & Summer & 1.31 & III & Moderately polluted \\
\cline { 2 - 5 } & Autumn & 1.11 & III & Moderately polluted \\
\hline \multirow{3}{*}{ Station II } & Spring & 1.99 & III & Moderately polluted \\
\cline { 2 - 5 } & Summer & 1.18 & III & Moderately polluted \\
\cline { 2 - 5 } & Autumn & 1.16 & III & Moderately polluted \\
\hline Station III & Spring & 1.81 & III & Moderately polluted \\
\cline { 2 - 5 } & Summer & 1.12 & III & Moderately polluted \\
\cline { 2 - 5 } & Autumn & 1.15 & III & Moderately polluted \\
\hline
\end{tabular}

The Spearman correlation analysis was performed to assess the relationships between the concentration of metals in fresh water. For this purpose, a correlation matrix was formed, reflecting the presence of positive statistically significant connections between individual metals (Table 8). The highest number of strong and significant $(p<0.05)$ correlations were found in lead, zinc, and aluminum. Firstly, these metals correlated with each other: $\mathrm{Pb}-\mathrm{Al}(\mathrm{r}=0.77), \mathrm{Pb}-\mathrm{Zn}(\mathrm{r}=0.82)$ and $\mathrm{Zn}-\mathrm{Al}(\mathrm{r}=0.94)$. Secondly, they were associated with water concentration of the same elements:

Lead $(\mathrm{Pb})$ with $\mathrm{Fe}(\mathrm{r}=0.75), \mathrm{Ni}(\mathrm{r}=0.72), \mathrm{Cu}(\mathrm{r}=0.79)$.

Zinc $(\mathrm{Zn})$ with $\mathrm{Fe}(\mathrm{r}=0.80), \mathrm{Ni}(\mathrm{r}=0.83), \mathrm{Cu}(\mathrm{r}=0.86)$.

Aluminum (Al) with $\mathrm{Fe}(\mathrm{r}=0.83)$, Ni $(\mathrm{r}=0.76), \mathrm{Cu}(\mathrm{r}=0.80)$. 
The smallest number of correlations was found in chromium and manganese, that is, metals having a variable degree of oxidation and, consequently, redox associated with reaction of the water medium.

In general, the correlation matrix showed that there are certain strong positive correlations between metals reflecting the interdependence of their concentrations in water [9, 10, 39$]$.

Table 7. Correlation matrix (by Spearman) of metals in reservoir water samples for 2019-2020

\begin{tabular}{|c|c|c|c|c|c|c|c|c|c|}
\hline Variable & $\mathrm{Al}$ & $\mathrm{Cr}$ & $\mathrm{Mn}$ & $\mathrm{Fe}$ & $\mathrm{Ni}$ & $\mathrm{Cu}$ & $\mathrm{Zn}$ & $\mathrm{Cd}$ & $\mathrm{Pb}$ \\
\hline $\mathrm{Al}$ & 1.00 & & & & & & & & \\
\hline $\mathrm{Cr}$ & 0.27 & 1.00 & & & & & & & \\
\hline $\mathrm{Mn}$ & 0.56 & 0.55 & 1.00 & & & & & & \\
\hline $\mathrm{Fe}$ & $0.83^{*}$ & 0.26 & 0.31 & 1.00 & & & & & \\
\hline $\mathrm{Ni}$ & $0.76^{*}$ & 0.17 & 0.36 & $0.70^{*}$ & 1.00 & & & & \\
\hline $\mathrm{Cu}$ & $0.80^{*}$ & 0.34 & $0.89^{*}$ & 0.57 & 0.64 & 1.00 & & & \\
\hline $\mathrm{Zn}$ & $0.94^{*}$ & 0.22 & 0.63 & $0.80^{*}$ & $0.83^{*}$ & $0.86^{*}$ & 1.00 & & \\
\hline $\mathrm{Cd}$ & 0.34 & $0.68^{*}$ & $0.68^{*}$ & 0.25 & 0.48 & 0.56 & 0.44 & 1.00 & \\
\hline $\mathrm{Pb}$ & $0.77^{*}$ & 0.36 & 0.63 & $0.75^{*}$ & $0.72^{*}$ & $0.79^{*}$ & $0.82^{*}$ & 0.51 & 1.00 \\
\hline
\end{tabular}

Note: ${ }^{*}$ - $\mathrm{p}<0.05$

Since regardless of the season of the year and the number of the sampling station the water in the reservoir was classified as "moderately polluted" by the WPI magnitude, we tried to determine priority factors in the formation of water quality structure, as well as their origin (natural, anthropogenic) with the help of PCA technique.

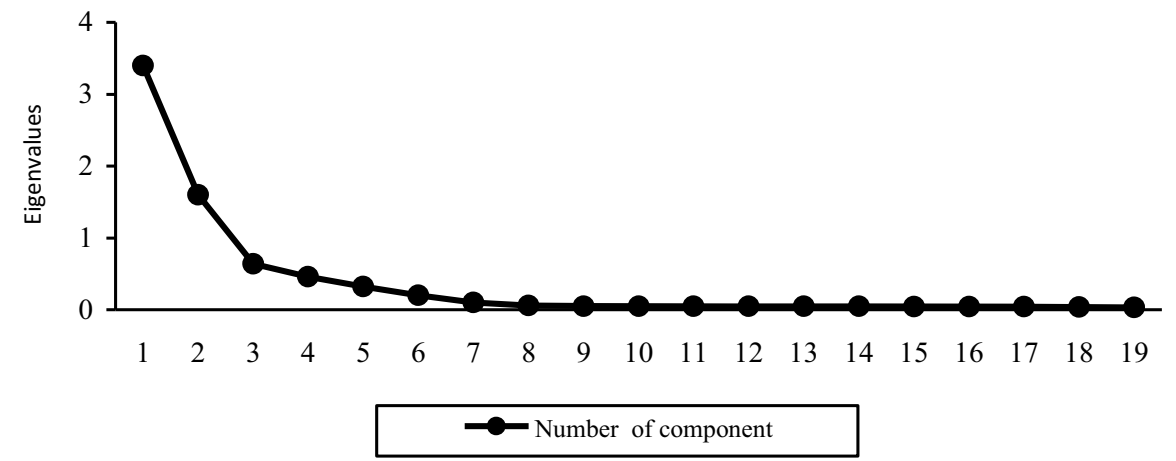

Fig. 2. Graphic criterion of Cattell's scree plot.

To highlight the main factors (the main components), we used the graphic criterion of Cattell's scree plot. As can be seen from Figure 2, only two factors' own values have exceeded one, the remaining components fell into the "factorial scree".

Table 8. Analysis of the main components forming the chemical composition of water in the reservoir

\begin{tabular}{|l|c|c|c|c|c|}
\hline \multirow{2}{*}{ Water parameters } & \multicolumn{2}{|c|}{ Main Component 1 } & \multicolumn{2}{|c|}{ Main Component 2 } & \multirow{2}{*}{$\begin{array}{c}\text { Cumulative } \\
\text { share of explained } \\
\text { variance }\end{array}$} \\
\cline { 2 - 5 } & Load & $P$ & Load & $P$ & 0.90 \\
\hline $\begin{array}{l}\text { Hydrogen ion expo } \\
\text { nent, pH }\end{array}$ & $\mathbf{- 0 . 8 6}$ & $<0.001$ & -0.37 & 0.11 & 0.70 \\
\hline Hydrocarbonates & $\mathbf{- 0 . 8 3}$ & $<0.001$ & 0.12 & 0.63 & 0.89 \\
\hline Chlorides & $\mathbf{0 . 9 4}$ & $<0.001$ & -0.10 & 0.70 & \\
\hline
\end{tabular}




\begin{tabular}{|c|c|c|c|c|c|}
\hline Sulphates & 0.91 & $<0.001$ & -0.34 & 0.17 & 0.94 \\
\hline Carbonates & 0.88 & $<0.001$ & 0.11 & 0.65 & 0.78 \\
\hline Fluorides & 0.86 & $<0.001$ & 0.12 & 0.65 & 0.95 \\
\hline Potassium & -0.86 & $<0.001$ & 0.11 & 0.59 & 0.81 \\
\hline Sodium & -0.80 & $<0.001$ & 0.24 & 0.16 & 0.72 \\
\hline Calcium & -0.82 & $<0.001$ & 0.07 & 0.75 & 0.85 \\
\hline Magnesium & -0.78 & $<0.001$ & 0.07 & 0.77 & 0.73 \\
\hline Aluminum & 0.84 & $<0.001$ & 0.15 & 0.55 & 0,73 \\
\hline Chromium VI & 0.79 & $<0.001$ & 0.63 & 0.01 & 0.97 \\
\hline Manganese & 0.78 & $<0.001$ & 0.60 & 0.01 & 0.98 \\
\hline Iron & 0.91 & $<0.001$ & 0.17 & 0.43 & 0.95 \\
\hline Nickel & 0.77 & $<0.001$ & 0.57 & 0.01 & 0.91 \\
\hline Copper & 0.88 & $<0.001$ & 0.21 & 0.41 & 0.81 \\
\hline Zinc & 0.88 & $<0.001$ & 0.24 & 0.34 & 0.83 \\
\hline Cadmium & 0.79 & $<0.001$ & 0.47 & 0.09 & 0.90 \\
\hline Lead & 0.75 & $<0.001$ & 0.56 & 0.01 & 0.93 \\
\hline $\begin{array}{l}\text { Explained } \\
\text { variance, \% }\end{array}$ & \multicolumn{2}{|c|}{69.3} & \multicolumn{2}{|c|}{16.9} & - \\
\hline$P$ & \multicolumn{2}{|c|}{$<0.001$} & \multicolumn{2}{|c|}{0,66} & - \\
\hline
\end{tabular}

Note: here and further, statistically significant effects are highlighted in bold $(P \leq 0.05)$

This gave reason to believe that the first two factors most significantly determine the water quality in the studied reservoir. Therefore, we have further presented information only for them (Table 8).

The main component 1 is statistically significant and explains $69.3 \%$ of the total variability of water quality parameters defined by us (Table 8). At the same time, all indicators gave strong and statistically significant factor loads on it. As it is known, the number of cations and anions in the reservoir's water is determined by the influence of natural (climate, precipitation, chemical rock weathering, dissolution of soil minerals) and anthropogenic factors (domestic and industrial wastewater, agricultural runoff) [40]. Since the concentration of such ions as potassium, sodium, calcium, magnesium, sulphates, chlorides, fluorides, carbonates and bicarbonates, aluminum, copper, zinc, and $\mathrm{pH}$ (Tables $4,5)$ were relatively low in relation to MPC [30] regardless of the year of research, season of year and station number, it is logical to assume that their level in the reservoir's water was maintained by natural origin sources. At the same time, the level of such metals as chromium VI, manganese, iron, and nickel, determining the degree of water contamination (Tables $5,6,7$ ) definitely depended not only on natural sources.

The main component 2 , although not generally statistically significant, but explained the variance of $16.9 \%$ variability in the sum of determined water chemical indicators. In it, statistically reliable factor loads were typical of cations such as chromium VI, manganese, nickel, cadmium, and lead. It is known that the circulation of toxic metals (cadmium, lead) in the environment is determined mainly by the influence of anthropogenic sources [33]. Therefore, the main component 2 , in which the contribution of these metals is statistically significant, reflects the water contamination degree in the reservoir due to anthropogenic effects.

The formation of the water quality structure can be judged not only by the analysis of the main components' contribution, but also by the magnitude of the residual unexplained variance [38], which is usually not considered by researchers. With this, the unaccounted factors are not necessarily random. 


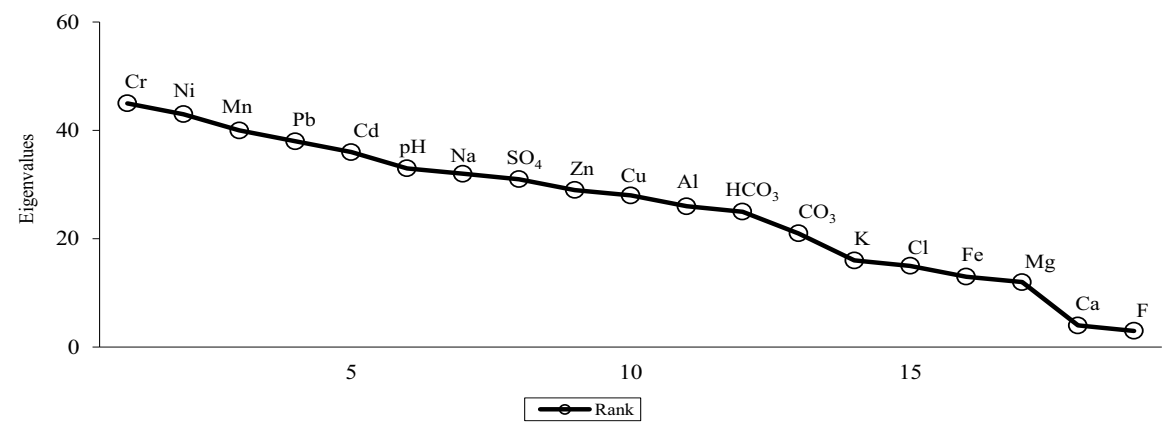

Fig. 3. Chemical indicators of water ranked by the share of unexplained variability.

The ranking of chemical water parameters by the value of the residual unexplained variance in descending order (Figure 3) showed that at the top of the chart are elements (chromium, nickel, manganese, lead, cadmium), the concentrations' formation of which in the reservoir's water is associated with the influence of anthropogenic factors as a result of specific pollution point sources' presence in the catchment of rivers feeding the reservoir. At the same time, despite excess level in water samples, such element as iron is located at the bottom of the chart. Consequently, the concentration of this metal in water is associated with the influence of factors forming the main components in the PCA method.

\section{Discussion}

Spatial and temporal variability of pollutants is specific to most water bodies [41]. The Troitsky reservoir (Chelyabinsk region, Russia) is not an exception.

The ecological water condition in the Troitsky reservoir is currently formed due to the supply of various chemicals in the feeding rivers' water. Their main sources are wastewater and flood water, soil. At the same time, the degree of wastewater treatment is a priority factor [41] since their discharge from urban water treatment plants occurs near the reservoir's headstream. Therefore, there was always a higher level of each parameter in water samples from the first station regardless of the season of the year. The identified anthropogenic nature of freshwater pollution is now typical for almost all aquatic ecosystems worldwide [13, 17, 42, 43, 44].

The lowest values of water parameters were found in the dam and the deepest part of the reservoir because of mineral compounds' settling to the bottom due to changes in solubility and sedimentation stability. Consequently, the spatial distribution of cations and anions across the reservoir water area reflected the level of anthropogenic load on the water object and the self-cleaning capacity of the aquatic ecosystem [16, 43].

Seasonal indicators' variability in water samples of the reservoir characterized both the efficiency of water buffer systems, the biota development, and the intensity of organic biomass decomposition $[17,39,43]$. During the summer-autumn period, the level of anions and cations in water significantly decreased compared to spring, providing both a decrease in MI and WPI magnitude. This was the result of metals' inclusion in the metabolic processes of living organisms, as well as the transition from the water to bottom sediments in conditions of $\mathrm{pH}$ displacement to the alkaline side and increase in water temperature [43]. 
However, estimated by the WPI, the water in the reservoir still corresponded to the "moderately polluted" category, which was the result of the anthropogenic load preservation on the reservoir in the studied seasons of the year.

Of trace elements, the content of manganese, chromium (VI), iron and nickel with both anthropogenic and natural origin had the greatest influence on water quality and environmental safety. The average value of the metal index for chromium (VI) in 2019 and 2020 amounted to 1.58 and 1.29 ; manganese -2.47 and 1.48 ; iron - 1.27 and 1.58 , nickel 1.25 and 1.30, confirming the presence of their common incoming source to the reservoir, as well as similar migratory activity in its ecosystem. According to [45], the main anthropogenic metals source to the reservoir-feeding rivers are discharges of JSC "Uchalinsky GOK" (Republic of Bashkortostan) specializing in mining and enrichment of copper-zinc pyritic ores. According to $[16,46]$, the industrial waters of mining enterprises are the most common anthropogenic source of metals in natural water bodies in most industrial regions of the world.

Dependence of metals' migratory mobility in reservoir water on the presence or geochemical relations between them, or common incoming sources, or similar chemical reactivity $[16,44]$ under the conditions of the studied aquatic ecosystem is confirmed by the presence of strong and significant correlations between individual elements. Thus, the largest number of strong correlations in such metals as aluminum, zinc and lead is associated with their amphoteric properties, enhanced by the $\mathrm{pH}$ shift from spring to autumn towards alkaline side [43]. At the same time, having variable valence, such metals as chromium and manganese are the most reactionary capable in an acidic environment. Therefore, they are little active, and do not affect the level of other metals under weakly alkaline water reaction conditions. In addition, the lack of correlation with other elements in chromium and manganese confirms their anthropogenic nature in water.

To confirm these conclusions, as well as to clarify the factors that determine the formation of the water quality structure in the reservoir, the method of unlimited analysis technique of the main components was used. With the help of PCA, it was revealed that the annual, seasonal, and intra-reservoir variability of the chemical water composition was determined by two main components by $86.2 \%$. Main Component 1 , which had a share of the explained variance of $69.3 \%$, reflected the impact of natural sources associated with geochemical characteristics of catchment areas on water quality. Therefore, the factorial load on parameters such as potassium, sodium, calcium, magnesium, sulphates, chlorides, fluorides, carbonates and bicarbonates, aluminum, copper, zinc and $\mathrm{pH}$ was greatest [40 ]. Main component 2, which had a share of the explained variance of $16.9 \%$, reflected the impact of anthropogenic impacts caused by the entry of various wastewater into the water source on water quality [33]. This is evidenced by statistically reliable factor loads of chromium VI, manganese, nickel, cadmium, and lead.

When assessing the water ions contribution to the formation of its quality by the value of the residual unexplained variance, it was found that the priority cations are chromium (VI), nickel, manganese, lead and cadmium of anthropogenic origin according to the PCA method. Consequently, these metals enter the reservoir by wastewater discharge from specific anthropogenic sources.

\section{Conclusions}

1. The cathode-anion composition of water in the reservoir and its ecological safety by metal level depends on the season of the year and the movement of the water mass from the headstream to the dam. The highest level of cations and anions is found in samples of spring water due to flood waters flowing into the feeding rivers and the reservoir, the smallest - in summer and autumn due to their inclusion in the biota processes, faster 
oxidation and migratory mobility. The maximum level of cations and anions is present in water samples from the upper part of the reservoir due to the wastewater discharge from urban water treatment plants. This is additionally superimposed on the chemical composition of the reservoir's feeding rivers water. During the movement of water from the headstream to the dam in the absence of man-made load from SDPP, the concentration of cations and anions decreases, reflecting the restorative potential of the aquatic ecosystem.

2. Estimating the content of metals in water samples from the reservoir by the magnitude of the metal index allows to rank them in the following order:

2019: $\mathrm{Mn}>\mathrm{Cr}(\mathrm{VI})>\mathrm{Fe}>\mathrm{Ni}>\mathrm{Cd}>\mathrm{Pb}>\mathrm{Al}>\mathrm{Cu}>\mathrm{Zn}$;

2020: $\mathrm{Fe}>\mathrm{Mn}>\mathrm{Ni}>\mathrm{Cr}(\mathrm{VI})>\mathrm{Cd}>\mathrm{Pb}>\mathrm{Al}>\mathrm{Cu}>\mathrm{Zn}$.

In terms of metals' index for chromium (VI), manganese (excluding the year of 2019), iron and nickel, water corresponds to the "slightly polluted" category; cadmium and lead "clean"; aluminum, copper, and zinc - "clean".

3. An assessment of water quality by the value of the integrated water pollution index (WPI) in 2019-2020 shows that it belongs to the 3rd quality class and is characterized as moderately polluted. WPI values are the highest in spring: in the headstream of the reservoir - 2.63; in the central - 2.26 and at the dam - 1.63. In summer and autumn, WPI ranges from 1.11 to 1.31 .

4. The number of strong and statistically significant correlations between metals in water is determined by the chemical features of the elements and pollution sources. Being ampholytes, lead, aluminum and zinc increase their reactivity in water with a slightly alkaline medium reaction and due to this directly affect not only the concentration of each other $\left(\mathrm{r}_{(\mathrm{Pb}-\mathrm{Al})}=0.77, \mathrm{r}_{(\mathrm{Pb}-\mathrm{Zn})}=0.82, \mathrm{r}_{(\mathrm{Zn}-\mathrm{Al})}=0.94\right)$, but also iron level $\left(\mathrm{r}_{(\mathrm{Pb}-\mathrm{Fe})}=0.75, \mathrm{r}_{(\mathrm{Zn}-}\right.$ $\left.\mathrm{Fe})=0.80, \mathrm{r}_{(\mathrm{Al}-\mathrm{Fe})}=0.83\right)$, nickel $\left(\mathrm{r}_{(\mathrm{Pb}-\mathrm{Ni})}=0.72, \mathrm{r}_{(\mathrm{Zn}-\mathrm{Ni})}=0.83, \mathrm{r}_{(\mathrm{Al}-\mathrm{Ni})}=0.76\right)$ and copper $\left(\mathrm{r}_{(\mathrm{Pb}-}\right.$ $\left.\mathrm{Cu})=0.79, \mathrm{r}_{(\mathrm{Zn}-\mathrm{Cu})}=0.86, \mathrm{r}_{(\mathrm{Al}-\mathrm{Cu})}=0.80\right)$.

5. The formation of annual, seasonal, and intra-reservoir variability of the cathode-anion water composition in the reservoir by the results of PCA is $86.2 \%$ due to the influence of two main components. The main component 1 reflects the impact of natural sources on water quality, main component 2 - anthropogenic. When ranking water indicators by the amount of residual unexplained variance, it was found that such priority pollutants as chromium (VI), nickel and manganese enter the reservoir from specific anthropogenic sources.

The results of the studies determine the need for continuous monitoring of water quality not only in the reservoir, but also in the rivers that feed it. In addition, it is recommended to monitor and increase the degree of wastewater treatment of urban water treatment plants.

\section{References}

1. Y. Yu, P. Wang, Ch. Wang, X. Wang, B. Hu, Int. J. Environ Res Public Health, 15(10), 2118 (2018) doi: 10.3390/ijerph15102118

2. M. Liro, V. Ruiz-Villanueva, P. Mikuś, B. Wyżga, E. Bladé Castellet, Sci Total Environ. 744, 140555 (2020) doi: 10.1016/j.scitotenv.2020.140555

3. M. Varol, Environ Res., 187, 109664 (2020) doi: 10.1016/j.envres.2020.109664

4. G. Sprinğge, M. Bērtiņš, L. Gnatyshyna, I. Kokorīte, A. Lasmane, V. Rodinov, O. Stoliar, Ambio, Online ahead of print (2021) doi: 10.1007/s13280-020-01470-1.

5. M. Liro, Sci Total Environ., 651(2), 2899-2912 (2019) doi: 10.1016/j.scitotenv.2018.10.138

6. X. Zhu, M. Zhang, X. Dong Qu, W. Qi Peng, L. Fei Duan, Ying Yong Sheng Tai Xue Bao, 29(11), 3847-3856 (2018) doi: 10.13287/j.1001-9332.201811.036 
7. T. Jiang, W.W. Lin, Y.J. Cao, K. Li, Y.X. Xuan, R. Li, J.Y. Chen, Huan Jing Ke Xue, 41(12), 5410-5418 (2020) doi: 10.13227/j.hjkx.202003018

8. P.M. Gurgel, J.A. Navoni, D.M. Ferreira, V.S. Amaral, Sci Total Environ., 572, 324332 (2016) doi: 10.1016/j.scitotenv.2016.08.002

9. M.S. Bhuyan, M.A. Bakar, Environ Sci Pollut. Res Int. 24(35), 27587-27600 (2017) doi: 10.1007/s11356-017-0204-y

10. Y. Cao, K. Lei, X. Zhang, L. Xu, Ch. Lin, Y. Yang, Ecotoxicol Environ Saf. 164, 210 218 (2018) doi: 10.1016/j.ecoenv.2018.08.009

11. R.P. Gomes, J.A.P. Silva, M.C.C. Junior, W.C.A. Alburquerque, P.S. Scalize, A.R.G. Filho, D. de J. Pires, J.D.G. Vieira, L.C. Carneiro, Environ Geochem Health. 41(6), 2425-2442 (2019) doi: 10.1007/s10653-019-00292-9

12. Y.Y. Rindita, R.K. Cahyani, Journal of Natural Remedies 21, 10(2), 1-9 (2021)

13. R.I. Bastanov, M.A. Derkho, K.A. Korlyakov, D.Yu. Nokhrin Astrakhan Bulletin of Ecological Education 3 (45), 163-168 (2018)

14. L.G. Muhamedyarova, M.A. Derkho, G.V. Meshcheriakova, O.A. Gumenyuk, S.S. Shakirova, Agronomy Research 18(2), 483-493 (2020)

15. M. Derkho, L. Mukhamedyarova, G. Rubjanova, P. Burkov, T. Schnyakina, P. Shcherbakov, T. Shcherbakova, K. Stepanova, G. Kazhibayeva, Inter. Journal of Veterinary Science 8(2), 61-66 (2019)

16. S.S. Withanachchi, G. Ghambashidze, I. Kunchulia, T. Urushadze, A. Ploeger, Int J Environ Res Public Health 15(4), 621(2018) doi: 10.3390/ijerph15040621

17. D.Yu. Nokhrin, Ecological and veterinary-sanitary state of reservoirs of Chelyabinsk region: monograph, 226 (2020)

18. GOST 51592 - 2000, Water, General requirements for sampling, 5 (2000)

19. PND F 14.1:2:3:4.121-97 Quantitative chemical analysis of water. Methods of measuring $\mathrm{pH}$ of water samples by potentiometric method, 13 (2018)

20. PND F 14. 1:2 .101-97 Quantitative chemical analysis of water. Method of measuring mass concentration of dissolved oxygen in samples of natural and treated wastewater by iodometric method. Access mode: https://files.stroyinf.ru/Data2/1/4293846/4293 846286.htm (access date 20.02.2021)

21. NDP 10.1:2:3.131-2016. Determination methods of biochemical oxygen demand after 5 days of incubation (BOD5) in samples of drinking, natural and wastewater by amperometric method, 23 (2016)

22. GOST 31957 - 2012 Determination methods of alkalinity and mass concentration of carbonates and bicarbonates, 25 (2013)

23. PND F 14.1:2:3.96-97. Quantitative chemical analysis of water. Methods of measuring mass concentration of chlorides in samples of natural and treated wastewater by argentometric method, 20 (2016)

24. PND F 14.1:2.159-2000. Quantitative chemical analysis of water. Measurement methods of sulphate-ions mass concentration in samples of natural and wastewater by turbidimetric method [http://docs.cntd.ru/document/1200075508 (access date: 15.12.2021)

25. PND F 14.1:2:3:4.179-2002. Quantitative chemical analysis of water. Measurement methods of fluoride ions mass concentration in drinking, surface, underground fresh and wastewater by photometric method with lanthanum (cerium) alizarine complexone, $23(2012$ 
26. GOST 31869-2012. Water. Methods for determining the content of cations (ammonium, barium, potassium, calcium, lithium, magnesium, sodium, strontium) using capillary electrophoresis, 23 (2019)

27. GOST 18165-2014 Water. Methods for determining aluminum content, 25 (2019)

28. PND F 14.1:2:4.50-96. Quantitative chemical analysis of water. Methods of measuring mass concentration of total iron in drinking, surface, and wastewater by photometric method with sulfosalicylic acid, 20 (2011)

29. PND F 14.1:2:4.139-98. Quantitative chemical analysis of water. Methods of measuring mass concentrations of iron, cobalt, manganese, copper, nickel, silver, chromium, and zinc in samples of drinking, surface and wastewater by atomic absorption spectrometry method, files.stroyint.ru/Index $2 / 1 / 493832 / 429832535 / \mathrm{htm}$ (access date: 15.12 .2021 )

30. GN 2.1.5.1315-03 Maximum permissible concentrations (MPC) of chemicals in water bodies of drinking and cultural-domestic water use http://docs.cntd.ru/document/901862249 (access date: 20.02.2021)

31. G. Bakan, H.B. Özkoç, S. Tülek, H. Cüce, Turk. J. Fish. Aquat. Sci., 10, 453-462 (2010) doi: 10.4194/trjfas.2010.0403

32. E.V. Pimenova, T.Yu. Nasrutdinova, S.V. Likhachev, Hygienic and ecological normalization of environmental quality, 151 (2017)

33. O.V. Gagarina, Evaluation and rationing of the natural waters' quality: criteria, methods, existing problems, 199 (2012)

34. I.T. Joliffe, Principal component analysis. N.Y, Springer-Verlag, 488 (2002) doi: $10.1007 / \mathrm{b} 98835$

35. D.A. Jackson, Ecology, 74(8), 2204-2214 (1993)

36. J. Oksanen, F.G. Blanchet, M. Friendly, R. Kindt, P. Legendre et al. Package 'vegan'. Community Ecology Package Version 2.5-7 (2020) URL: https://github.com/vegandevs/vegan (access date: 01.05.2021)

37. R Core Team. R: A language and environment for statistical computing. Austria, Vienna: R Foundation for Statistical Computing, URL: https://www.R-project.org (access date: 02.05.2021) (2016)

38. D.Yu. Nokhrin, Yu.G. Gribovsky, N.A. Davydova Ecology, 4, 369-375 (2011)

39. R.I. Bastanov, M.A. Derkho Scholars notes of the Crimean Federal University named after V.I. Vernadsky, Biology. Chemistry 4 (70), 1, 5-14 (2018)

40. L. Xiao, Q. Zhang, C. Niu, H. Wang, J Environ Res Public Health, 17(14), 5015 (2020) doi: 10.3390/ijerph17145015

41. I. Zykova, N. Maksimuk, M. Rebezov, E. Kuznetsova, M. Derkho, T. Sereda, G. Kazhibayeva, Y. Somova, T. Zaitseva, ARPN Journal of Engineering and Applied Sciences, 14(11), 2139-2145 (2019)

42. K.Th. Nguyen, H.M. Nguyen, C.K. Truong, M.B. Ahmed, Y. Huang, J.L. Zhou, Environ Geochem Health, 41(6), 2559-2575 (2019) doi: 10.1007/s10653-019-00302-w

43. V.M. Artemenko, Yu.P. Ilyin, V.S. Kucherenko, A.I. Ryabinin, S.A. Bobrova, A.N. Gutsalyuk, Yu.A. Malchenko, L.V. Saltykova Environmental safety of coastal and shelf zones and integrated use of shelf resources, 12, 129-148 (2005)

44. A. Baran, M. Tarnawski, T. Koniarz, Environ. Sci. Pollut. Res., 23, 17255-17268 (2016) doi: 10.1007/s11356-016-6678-1 
45. M.G. Opekunova, A.Yu. Opekunov, V.V. Somov, E.S. Mitrofanova, E.E. Papyan, Proceedings of the Biogeochemical Laboratory, 25, 524-536 (2016)

46. F. Ferati, M. Kerolli-Mustafa, A. Kraja-Ylli, Environ Monit Assess., 187(6), 338 (2015) doi: 10.1007/s10661-015-4524-4 